\title{
A Strategic Approach Using Representative LV Networks in the Assessment of Technical Losses on LV Network with Solar Photovoltaic
}

\author{
Jun Huat Tang ${ }^{\# *}$, Mau Teng Au* ${ }^{*}$ Hussain Shareef ${ }^{\$}$, A.M.Busrah ${ }^{\#}$, \\ ${ }^{\#}$ Distribution Research Group, TNB Research Sdn Bhd, No. 1, Lorong Ayer Itam, Selangor, 43000, Malaysia \\ E-mail: jun.huat@tnb.com.my; asnawi.busrah@tnb.com.my \\ *Institute of Power Engineering, Univeriti Tenaga Nasional, 43000 Kajang, Selangor, Malaysia \\ E-mail:mtau@uniten.edu.my \\ ${ }^{\$}$ Department of Electrical Engineering, U.A.E University, Al-Ain, United Arab Emirates \\ E-mail: hussain_ln@yahoo.com
}

\begin{abstract}
Low voltage network (LVN) forms an extensive part of the distribution network as it is used to connect electricity supply from utility substations to diverse segments of loads in different geographic locations. With the increasingly high penetration of solar PV in LVN, utility companies are finding it necessary to establish the contribution of this solar PV to the overall technical losses in the distribution network. This paper presents a strategic approach using representative LVN to determine the impact of solar PV on technical losses on the LVN. Five types of representative LVN characterized by different customer load segments (domestic, commercial and industrial) and peak load demand were developed. The impact on technical losses of solar PV connected to these representatives LVN was assessed on a statistical basis for a supply zone. The results obtained are consistent and could be applied to establish investment strategies on the distribution network, tariff revision exercise and optimization of distribution network planning/design.
\end{abstract}

Keywords - solar pv; technical losses; distribution system; representative network

\section{INTRODUCTION}

In recent years, the penetration of renewable energy $(\mathrm{RE})$ and distributed generation (DG) has increased significantly due to cost reduction through the economies of scale, strong support from government subsidies, and the awareness of environmental issues. RE generation mix in global electricity production by the end of 2014 is $22.8 \%$. The share of the RE generation mix consists of $16.6 \%$ contributions from hydropower, $3.1 \%$ from the wind, $1.8 \%$ from Bio-power, $1.8 \%$ of solar PV and $0.4 \%$ of geothermal, concentrating solar power and ocean energy. The world total installed capacity for the wind and solar power is $370 \mathrm{GW}$ and $177 \mathrm{GW}$ respectively.

The existence of DG in distribution network changes the planning and operation of the conventional distribution network. Hence, many in-depth studies have been carried out to investigate the impact of DG on the distribution network. Technical issues arise from the DG interconnection include voltage rise, higher system fault level, mal-tripping of protection relay and reverse power flow [1].

Technical losses are one of the indicators for distribution network efficiency. Distribution Network Company (DISCO) came out with different approaches to estimate the technical losses in the distribution network and subsequently manage and minimize the losses. In the past, many research works have been carried out to estimate the technical losses of large distribution network without considering the participation of DG [2]-[6]. The conventional approach in estimating technical losses is generally useful for utility companies in determining the technical losses. Equivalent hour of losses [3], load loss factor [2] and loss coefficient method [5] are well-established methods and being used by DISCO to assess technical losses in the network. These methods are simple to use and produce acceptable results.

A number of researches reported on the benefits of DG such as reduction in technical losses, deferment of infrastructure development and improve system reliability. However, it is reported in [7] that there could be an increase 
in technical losses if the network is congested with DG. Using simulation and analysis, [8] established a U-shaped trajectory relationship between DG penetration level and network losses. In addition, the technical losses due to DG are influenced by various factors such as DG power factor, network topology and load pattern [7], [9]-[12]. All these factors contribute to the complexity of assessing the impact of DG on technical losses in the distribution network. The majority of published researches are focused on the impact of DG on technical losses of a small or specific network without considering the overall impact on the whole distribution network/system or supply zone [8], [13]-[18]. Technical losses assessment on a large distribution network poses a challenge because of the extensive variations in network configurations, diverse load profiles from a different combination of load segments [6], and the randomness of DG connection points and its capacity [13].

This paper presents a strategic approach to the assessment of technical losses in low voltage (LV) distribution network connected with solar PV, using representative networks. LV distribution networks are categorized into five types of representative networks. Quasi-dynamic simulations were carried out to quantify the technical losses of the representative LVN considering solar PV penetration level, customer load segments, and network peak demand. The LVN technical losses of a supply zone are then be evaluated based on the number of each representative LVN in the supply zone and results on technical losses established from quasi-dynamic simulation results.

\section{MATERIAL AND METHOD}

Fig. 1 shows the typical distribution network in Malaysia. It consists of $33 \mathrm{kV}, 11 \mathrm{kV}$ and $0.4 \mathrm{kV}$ network. This paper will focus on the $0.4 \mathrm{kV}$ or LVN network.

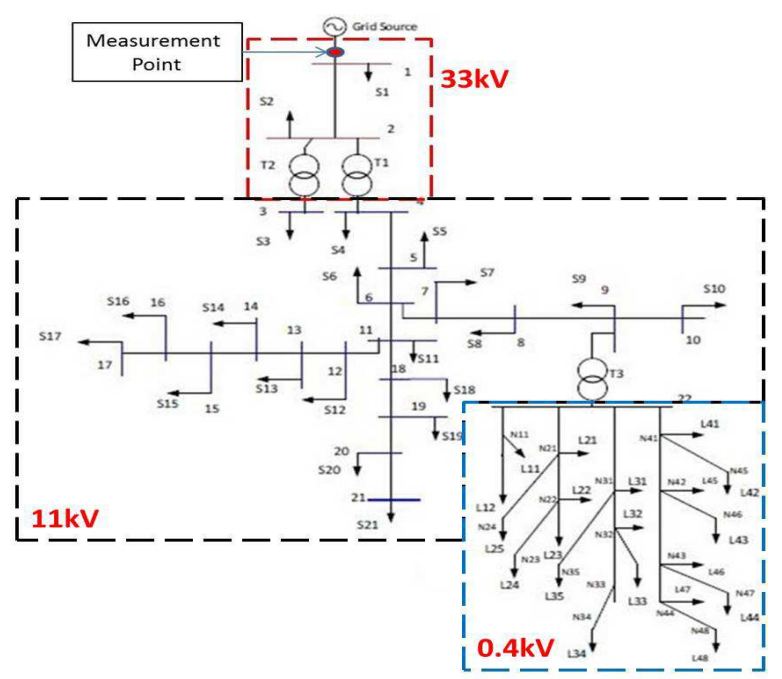

Fig. 1 Distribution network diagram

Technical losses in LVN are primarily influenced by its network topologies, connected load types, load demand and DG penetration levels. With the wide range of parameters that could affect the technical losses level of an LV network, it is therefore difficult to generalize a relationship between the LV network technical losses against different levels of DG penetration. In this paper, representative LVN characterized by its topologies, customer load types, and peak load demand are used to develop a strategic approach to estimating the technical losses associated with the different levels of solar PV (SPV) penetration.

\section{A. LV Representative Network}

The configurations and topologies of LV distribution networks are planned and constructed based on standard design and guidelines dictated by the type of development. Therefore, it is generally possible to classify LV distribution network into a specific number of categories. The five types of LVN, namely LVT-1, LVT-2, LVT-3, LVT-4 and LVT-5 discussed below were developed to represent the Malaysian LV distribution network,

1) LVT-1: Underground System for Commercial/ Industrial Loads. These are LVN which feed commercial shop lots in urban areas or small industrial premises. The typical design utilizes underground cable connections from feeder pillars to Main Switch Board (MSB) of each lot of commercial/industrial customer. This design consists of $2 \mathrm{x}$ 300 sq.mm XLPE AL 4C cable from the main 1600A feeder pillar of the substation to 800 A sub-feeder pillars. The LV service cables to a customer of MSB are 70 sq.mm XLPE AL 4C.

2) LVT-2: Underground System for Domestics Loads. These are LVN which feed domestic loads in urban areas. The typical design utilizes underground cables for aesthetic reasons. This design connects 2 × 300 sq.mm XLPE AL 4C cable from the main 1600A feeder pillar of the substation to 800 A sub-feeder pillars and 1 x 185 sq.mm XLPE AL 4C from sub feeder pillars to $400 \mathrm{~A}$ mini feeder pillar. LV service cables are made up of $25 \mathrm{~mm}$ sq. XLPE AL $4 \mathrm{C}$ from mini feeder pillar to customer meter panel.

3) LVT-3: Overhead System for Link/Terrace Houses Domestic Loads. These are LVN which feed link/terrace houses. The typical design consists of connecting a 1 x 185 sq.mm XLPE AL 4C from the main feeder pillar of the substation to the pole and using 1 x $3 \times 185+120+16$ sq.mm $\mathrm{LV}$ aerial bundled conductor (ABC) to form the overhead mains. Insulated Al 19.064 PVC are used as five foots way mains to connect to customer meters.

4) LVT-4: Overhead System for Domestic Rural Loads. These are LVN which feed houses in rural areas. The feeders are overhead line system characterized by long feeder length and low load demand per circuit.

5) LVT-5: Overhead System for Commercial/Industrial Loads. These are LVN which feed shop lots and small industrial premises. The typical design consists of connecting a 1 x 185 sq.mm XLPE AL 4C from the main feeder pillar of the substation to the pole and using $3 \mathrm{x} 1 \mathrm{x}$ $185+120+16$ sq.mm, LV ABC to form the overhead mains. Insulated $\mathrm{Al} 19.064 \mathrm{PVC}$ are used as five foots way mains to connect to customer meters. 
TABLE I

Peak Demand, Spv Penetration And Technical Losses of LVN

\begin{tabular}{|c|c|c|c|c|c|c|c|}
\hline \multicolumn{3}{|c|}{ RN Type } & $L V T-1(i=1)$ & $L V T-2(i=2)$ & $L V T-3(i=3)$ & $L V T-4(i=4)$ & $L V T-5(i=5)$ \\
\hline $\begin{array}{c}\% \text { Peak } \\
\text { Demand }\end{array}$ & $\begin{array}{c}\text { Solar PV } \\
\text { Penetration }\end{array}$ & & & & & & \\
\hline \multirow{8}{*}{$\begin{array}{c}\mathrm{Pk}-25 \% \\
(\mathrm{k}=1)\end{array}$} & \multirow[t]{2}{*}{$S P V-0(j=1)$} & TL (kWh) & 52.76 & 56.33 & 48.51 & 57.11 & 53.84 \\
\hline & & No of LVN & $n(1,1,1)$ & $n(2,1,1)$ & $n(3,1,1)$ & $n(4,1,1)$ & $n(5,1,1)$ \\
\hline & \multirow[t]{2}{*}{$S P V-3(j=2)$} & TL (kWh) & 50.88 & 55.55 & 48.02 & 55.26 & 51.71 \\
\hline & & No of LVN & $n(1,2,1)$ & $n(2,2,1)$ & $n(3,2,1)$ & $n(4,2,1)$ & $n(5,2,1)$ \\
\hline & \multirow[t]{2}{*}{$S P V-6(j=3)$} & TL (kWh) & 49.14 & 54.86 & 47.4 & 54.91 & 49.22 \\
\hline & & No of LVN & $n(1,3,1)$ & $n(2,3,1)$ & $n(3,3,1)$ & $n(4,3,1)$ & $n(5,3,1)$ \\
\hline & \multirow[t]{2}{*}{$S P V-9(j=4)$} & TL (kWh) & 47.52 & 54.52 & 47.2 & 55.23 & 47.7 \\
\hline & & No of LVN & $n(1,4,1)$ & $n(2,4,1)$ & $n(3,4,1)$ & $n(4,4,1)$ & $n(5,4,1)$ \\
\hline \multirow{8}{*}{$\begin{array}{c}P k-50 \% \\
(k=2)\end{array}$} & \multirow[t]{2}{*}{$S P V-0(j=1)$} & TL (kWh) & 112.5 & 127.17 & 94.69 & 130.94 & 116.9 \\
\hline & & No of LVN & $n(1,1,2)$ & $n(2,1,2)$ & $n(3,1,2)$ & $n(4,1,2)$ & $n(5,1,2)$ \\
\hline & \multirow[t]{2}{*}{$S P V-3(j=2)$} & TL (kWh) & 108.41 & 125.42 & 93.59 & 126.07 & 112.11 \\
\hline & & No of LVN & $n(1,2,2)$ & $n(2,2,2)$ & $n(3,2,2)$ & $n(4,2,2)$ & $n(5,2,2)$ \\
\hline & \multirow[t]{2}{*}{$S P V-6(j=3)$} & TL (kWh) & 104.37 & 123.63 & 92.09 & 123.24 & 106.5 \\
\hline & & No of LVN & $n(1,3,2)$ & $n(2,3,2)$ & $n(3,3,2)$ & $n(4,3,2)$ & $n(5,3,2)$ \\
\hline & \multirow{2}{*}{$S P V-9(j=4)$} & TL (kWh) & 100.34 & 122.21 & 91.28 & 122 & 102.64 \\
\hline & & No of LVN & $\mathrm{n}(1,4,2)$ & $n(2,4,2)$ & $n(3,4,2)$ & $n(4,4,2)$ & $n(5,4,2)$ \\
\hline \multirow{8}{*}{$\begin{array}{c}P k-75 \% \\
(k=3)\end{array}$} & \multirow[t]{2}{*}{$S P V-O(j=1)$} & TL (kWh) & 216.27 & 250.44 & 174.11 & 260.37 & 226.09 \\
\hline & & No of LVN & $n(1,1,3)$ & $n(2,1,3)$ & $n(3,1,3)$ & $n(4,1,3)$ & $n(5,1,3)$ \\
\hline & \multirow{2}{*}{$S P V-3(j=2)$} & TL (kWh) & 209.77 & 247.68 & 172.38 & 252.32 & 218.51 \\
\hline & & No of LVN & $n(1,2,3)$ & $n(2,2,3)$ & $n(3,2,3)$ & $n(4,2,3)$ & $n(5,2,3)$ \\
\hline & \multirow{2}{*}{$S P V-6(j=3)$} & TL (kWh) & 203.22 & 244.75 & 169.97 & 246.87 & 209.48 \\
\hline & & No of LVN & $n(1,3,3)$ & $n(2,3,3)$ & $n(3,3,3)$ & $n(4,3,3)$ & $n(5,3,3)$ \\
\hline & \multirow[t]{2}{*}{$S P V-9(j=4)$} & TL (kWh) & 196.56 & 242.2 & 168.54 & 243.98 & 203.08 \\
\hline & & No of LVN & $n(1,4,3)$ & $n(2,4,3)$ & $n(3,4,3)$ & $n(4,4,3)$ & $n(5,4,3)$ \\
\hline
\end{tabular}

\section{B. Technical Losses of Base Case LV Representative Network}

Technical losses level of the five $L V$ representative networks (LVT-1, LVT-2, LVT-3, LVT-4, and LVT-5) with no DG penetration (refer to as SPV-0 in Table 1) were established as base cases through quasi-dynamic simulation in DIgSILENT Power Factory software. Quasi-dynamic simulation consecutive power flow calculations on each time step of a set of load profiles that represent the time horizon under which a network needs to be analysed. Results of time series simulation are good for assessing network losses as it is expected to give more accurate results as compared to snap shot simulation. Under the time-series simulation, load profiles of specific time steps (e.g 15 minutes) are used to model load buses. Consequently, power flow and power losses through the individual network components (cables and transformers) are in time steps. Energy losses can be calculated by taking the area under the curve of the power loss profiles over a specified period of time without having to estimate using load factor.

In this study, quasi-dynamic simulation, half an hour interval load profile of domestic, commercial and industrial loads were applied to the respective representative feeder as input loads to the power flow simulation. Half an hour interval was selected because the majority of the energy meter record energy demand in half an hour or 15 minutes interval.

As can be observed from Fig. 2, both customer load types profiles and SPV generation profile are critical inputs to the load flow simulation and consequently the evaluation of technical losses in the network. Generally, commercial and domestic customer have different load profiles. Commercial load starts to increase at $7.00 \mathrm{a}$ am. and reach peak demand around $3.00 \mathrm{p} . \mathrm{m}$. and decreasing after that. This is similar to SPV generation profile. Whilst for domestic customer, the peak demand happened in the late evening, around 9.30 p.m.

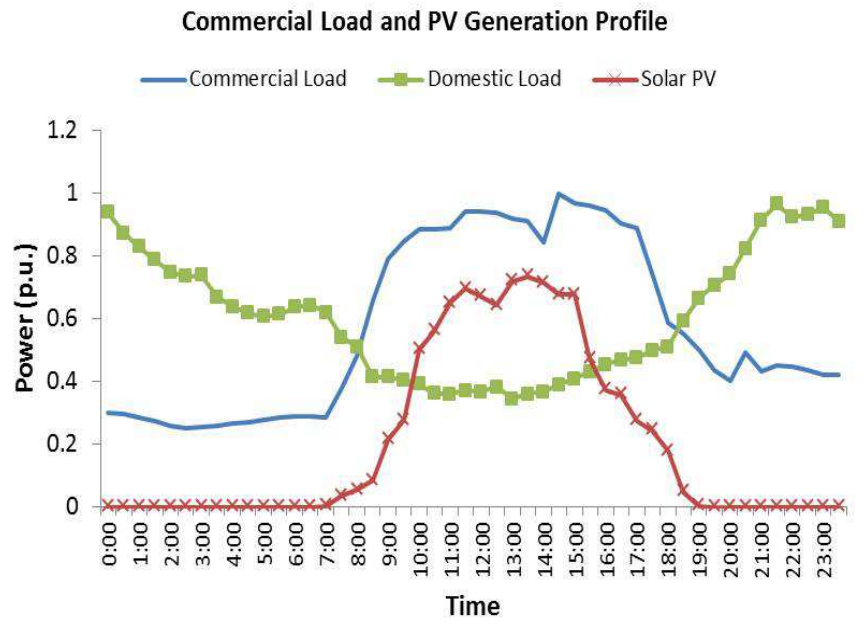

Fig. 2 Generic load and PV generation profile.

\section{Influence of Peak Demand on Technical Losses}

Peak demand has a significant influence on the network losses $\left(I^{2} R\right)$ due to the quadratic behaviour of the current component. The LVN is designed to be loaded up to a total peak demand of $1000 \mathrm{kVA}$ which corresponds to the maximum rated capacity of the $11 / 0.4 \mathrm{kV}$ transformer at the substation. The peak demand of the LVN is generally dependent on the maturity level of the network, its location, 
and demography. Hence, three peak demand scenarios of $25 \%, 50 \%$ and $75 \%$ (refer to as Pk-25, Pk-50, and Pk-75 in Table 1) of $1000 \mathrm{kVA}$ were selected for the simulation to determine the corresponding technical losses of the five representative $\mathrm{LVN}$ loaded to the respective peak loading scenario.

\section{Impact of LV Connected Solar PV on Technical Losses}

Solar PV connected to LVN generates and supply power to the loads within close proximity, thus modifying the load flow profile and peak demand of the $11 / 0.4 \mathrm{kV}$ transformer and feeders. Therefore, the impact of solar PV on technical losses is dependent on its total capacity connected to the LV network, the loading condition, and the PV injection point. In demand dominated distribution network, the solar generation reduces the current flow in the distribution network and hence reduce the network losses. However, in generation dominated network, solar generation caused higher current flow in the network and result in higher technical losses.

Statistically as shown in Fig. 3, in Malaysia, solar PV of capacity in the range of 8 to $12 \mathrm{~kW}$ are most commonly installed in LVN. This is due to the LV network capacity and available space for PV installation. Therefore are selected and placed randomly in each of the five representative networks of various penetration levels to determine its impact on the technical losses. Besides the base case which refers to zero penetration of solar PV (SPV-0 as shown in Table 1), three other penetration levels; that is $3 \times 12 \mathrm{~kW}$, $6 \times 12 \mathrm{~kW}$, and 9x12 kW (refer to as SPV-3, SPV-6, and SPV-9 respectively in Table 1) were simulated to determine the respective technical losses under three different peak demands (refer to Table 1 as Pk-25, Pk-50, and Pk-75).

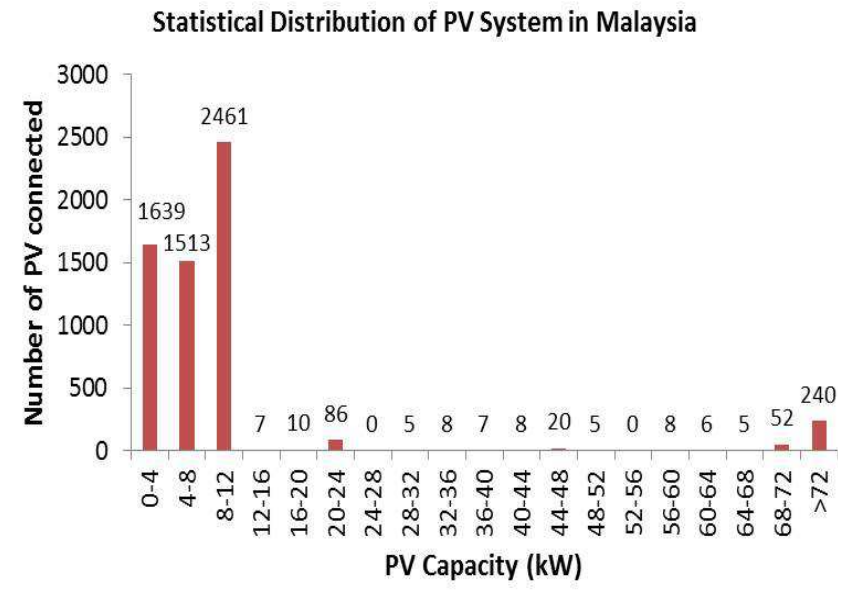

Fig. 3 Statistics of solar PV system in Malaysia

\section{E. Impact of Solar PV on Technical Losses of LV Network for a Supply Zone}

A supply zone typically comprises of a large number of distribution substations. LVN from each of the distribution substation could be classified as belonging to one of the five representatives LVN. In Table $1, n(i, j, k)$ is an array that denotes the number of LVT of the corresponding types of LVN (i), solar PV penetration (j), and peak demand (k) in the supply zone. For example, $n(2,3,1)=5$ implied that there are 5 numbers of LVN of type LVT-2 with PV penetration SPV-6, and peak demand Pk-25\% in the supply zone.

Correspondingly, from Table 1, the total TL contribution from LVT-2 type network in the supply zone is $54.86 \mathrm{kWh} \times$ $5=274.3 \mathrm{kWh}$.

Similarly, TL corresponding to each LVN, its PV penetration, and peak demand could be stored in an array of $i \times j \times k$.

Let $T L(i, j, k)$ represents the technical losses of the LVN in a supply zone where $i=1, \ldots, 5, j=1, \ldots, 4$, and $k=1, \ldots 3$.

The total technical losses of the LVN of the supply zone under study, with SPV connected, is estimated by taking the sum of the product of the elements from array $n(i, j, k)$ with the respective element of array $T L(i, j, k)$. The mathematical expression is as follows,

$$
T o t_{-} T L=\sum_{i=1}^{5} \sum_{j=1}^{4} \sum_{k=1}^{3} n(i, j, k) \times T L(i, j, k)
$$

From (1), the TL for base case, which is when the LVN of the supply zone is without any connection of solar PV, can be calculated based on the expression below,

$$
\text { Tot_TL_Base }=\sum_{i=1}^{5} \sum_{k=1}^{3} n(i, 1, k) \times T L(i, 1, k)
$$

Elements of the array are integer numbers representing the respective number of the LVN. Hence, the total number of LVN in the supply zone under study can be computed as follows,

$$
\text { Tot_LVN }=\sum_{i=1}^{5} \sum_{j=1}^{4} \sum_{k=1}^{3} n(i, j, k)
$$

\section{RESULTS AND DISCUSSION}

The performance of the LVN in terms of its technical losses for base cases is shown in Fig. 4. It can be observed that LVT-3 is the best performing LVN and LVT-4 is the worst. This is because LVT-3 have shorter cable/line and lower loading compare to other LVT. LVT-4 has longer cable/line to supply the remote customer at the rural area and hence higher heat losses due to resistance.

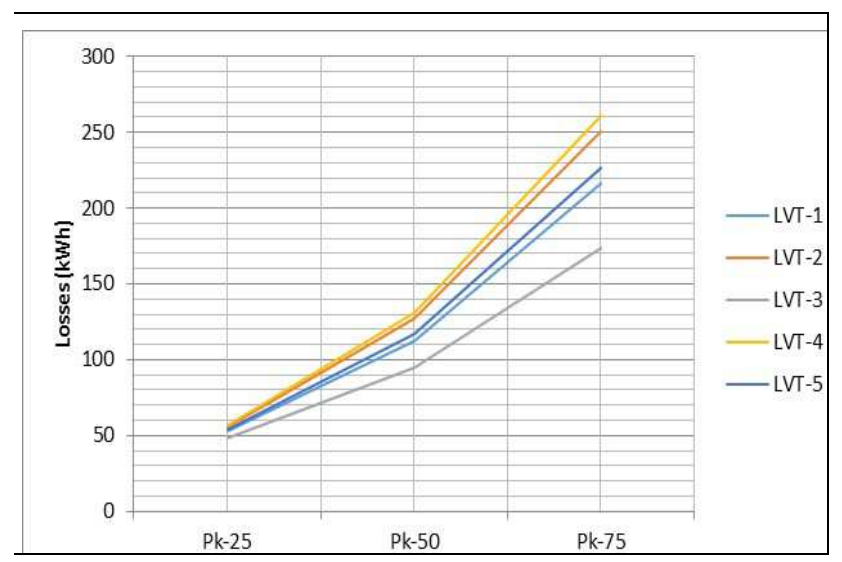

Fig. 4 Base case losses of the LVN 
Fig. 5 shows the technical losses of LVT in the presence of solar PV generation. Generally, technical losses of the distribution network reduce when the PV penetration increase except for LVT-4. In LVT-4, the technical losses slightly increase for SPV-9 because the PV generation is higher than the local demand, hence increase the network losses. The results showed that distributed generation sizing and placement is vital to improving distribution network efficiency.

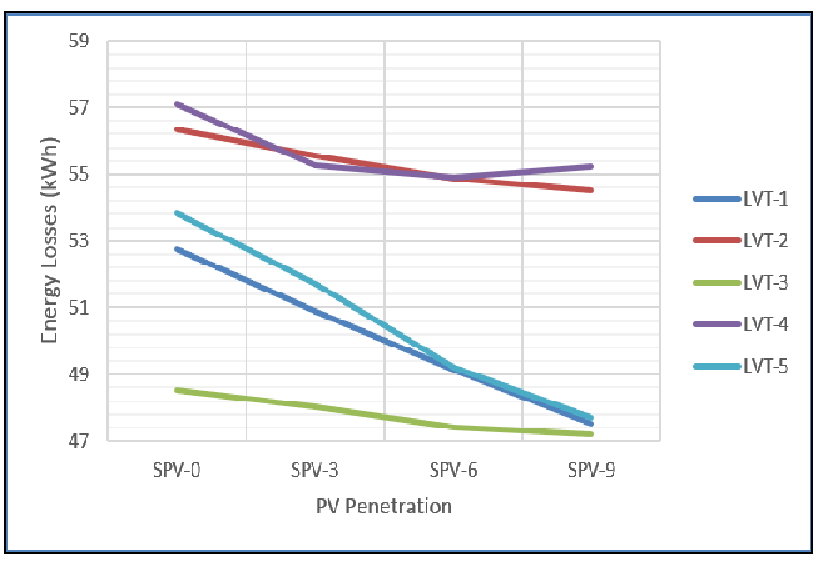

Fig. 5 Technical losses of the LVN with solar PV

With solar PV connection to the LVN, it is observed that LVT-5 is the most sensitive LVN in regards to the reduction of technical losses as shown in Fig. 6. This is because LVT-5 is a commercial network where solar PV power generation coincides with the network load demand, thereby supplying power close to the load point. Hence, solar PV generation significantly reduces the peak power flow and consequently the network technical losses.

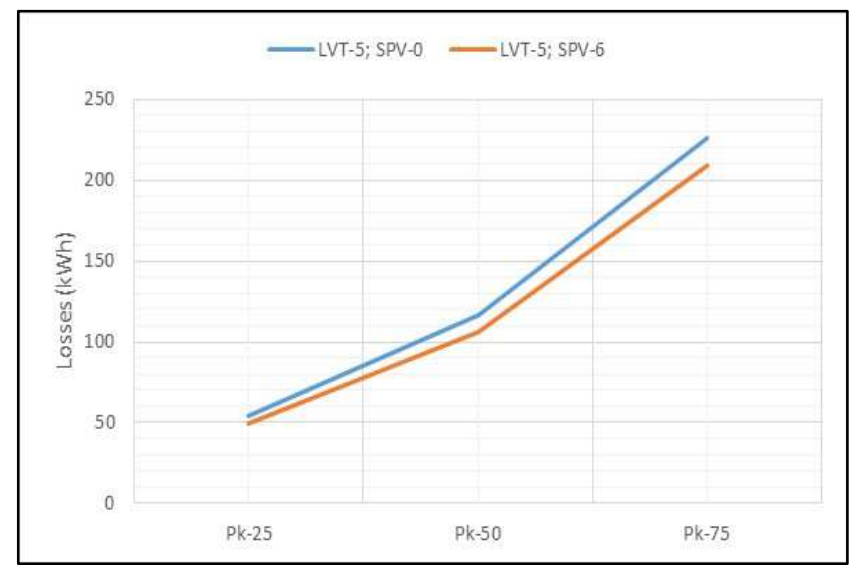

Fig. 6 LVT-5 - most sensitive LVN in technical losses reduction due to solar $\mathrm{PV}$ penetration

LVT-2 is the least sensitive because it is residential dominated distribution network as shown in Fig. 7. The peak demand of the network which occurs at night is not affected by the solar PV power generation. The main contributing factor which influences the sensitivity of LVN in regards to the reduction of technical losses due to solar PV is the customer load profile. LVN with commercial customer loads is more beneficial in terms of technical losses reduction than domestic load as solar PV generates maximum power at around noon period which coincides with the maximum load demand of commercial customer load.

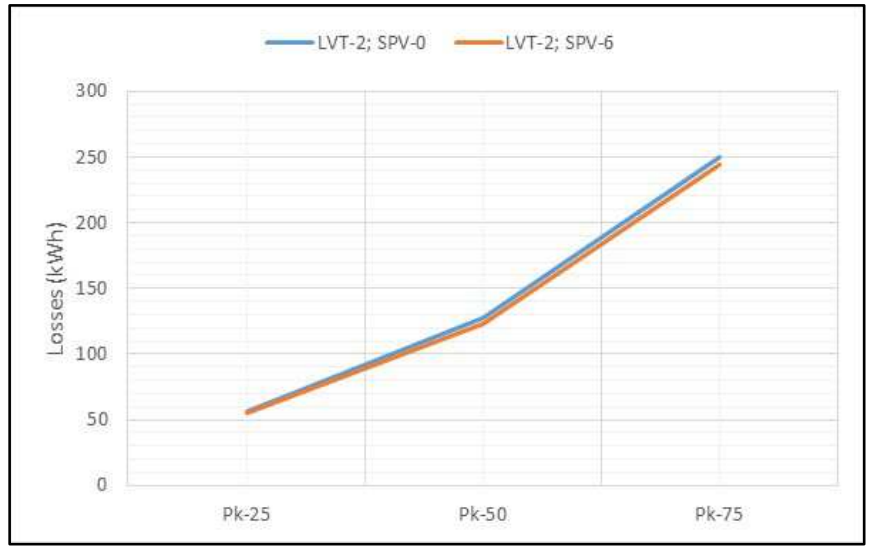

Fig. 7 LVT-2 - least sensitive LVN in technical losses reduction due to solar PV penetration

The case study below is to illustrate a strategic approach to evaluate the impact of solar PV connected at LV network on the technical losses of a supply zone. Two case studies are presented. The key difference between the two cases is their customer loads. The case I is a supply zone with predominantly domestic customers' loads, whereas Case II is a supply zone of similar size with predominantly commercial customer loads.

\section{A. Description of the Supply Zones}

1) Case I: The supply zone is a suburban area predominantly dominated by domestic customer loads. Two medium voltage $11 \mathrm{kV}$ feeders with a peak demand of approximately $2.5 \mathrm{MVA}$ per feeder are feeding a total of twenty (20) 11/0.4 kV distribution substations.

2) Case II: The supply zone is a suburban area predominantly dominated by commercial customer loads. Similar to Case I, two medium voltages $11 \mathrm{kV}$ feeders with a peak demand of approximately 2.5 MVA each are feeding a total of twenty (20)11/0.4 kV distribution substations.

It is assumed that each distribution substation $(11 / 0.4 \mathrm{kV})$ has a single type of LVN. This is assuming because the distribution substation is generally designed to supply a small geographical area, hence it is likely that the area has a similar type of customer. Therefore, the total number of LVN in each of the supply zone is 20.

The distribution of the number of LVN of the supply zone according to its solar photovoltaic penetration and peak demand, for Case I and Case II is given as an array as follows,

$$
\begin{aligned}
& n(i, j, k)=N(I)=\left[\begin{array}{llllllllllll}
0 & 0 & 0 & 0 & 0 & 0 & 1 & 0 & 1 & 0 & 0 & 0 \\
0 & 0 & 1 & 0 & 2 & 1 & 2 & 0 & 0 & 0 & 0 & 0 \\
1 & 0 & 1 & 0 & 3 & 0 & 2 & 4 & 0 & 1 & 0 & 0 \\
0 & 0 & 0 & 0 & 0 & 0 & 0 & 0 & 0 & 0 & 0 & 0 \\
0 & 0 & 0 & 0 & 0 & 0 & 0 & 0 & 0 & 0 & 0 & 0
\end{array}\right] \\
& n(i, j, k)=N(I I)=\left[\begin{array}{llllllllllll}
1 & 1 & 0 & 0 & 1 & 1 & 0 & 0 & 0 & 0 & 0 & 0 \\
0 & 0 & 1 & 0 & 0 & 0 & 1 & 0 & 0 & 0 & 0 & 0 \\
0 & 0 & 0 & 0 & 1 & 1 & 0 & 0 & 0 & 0 & 0 & 0 \\
0 & 0 & 0 & 0 & 0 & 0 & 0 & 0 & 0 & 0 & 0 & 0 \\
0 & 2 & 1 & 1 & 2 & 3 & 2 & 0 & 0 & 1 & 0 & 0
\end{array}\right]
\end{aligned}
$$


The base technical losses of the LVT shown in Table 1 is in an array form. Elements of an array representing technical losses of each scenario of solar photovoltaic penetration and peak demand of the respective low voltage networks as follows,

$$
\begin{array}{cccccccc}
T L(i, j, k)= & {\left[\begin{array}{ccccccc}
52.8 & 50.9 & 49.1 & 47.5 & 112.5 & 108.4 \\
56.3 & 55.6 & 54.9 & 54.5 & 127.2 & 125.4 \\
48.5 & 48.0 & 47.4 & 47.2 & 94.7 & 93.6 \\
57.1 & 55.3 & 54.9 & 55.2 & 130.9 & 126.1 \\
53.8 & 51.7 & 49.2 & 47.7 & 116.9 & 112.1 \\
104.4 & 100.3 & 216.3 & 209.8 & 203.2 & 196.6 \\
123.6 & 122.2 & 250.4 & 247.7 & 244.8 & 242.2 \\
92.1 & 91.3 & 174.1 & 172.4 & 170.0 & 168.5 \\
123.2 & 122.0 & 260.4 & 252.3 & 246.9 & 244.0 \\
106.5 & 102.6 & 226.1 & 218.5 & 209.5 & 203.1
\end{array}\right]} &
\end{array}
$$

\section{B. Technical Losses Estimation}

The total technical losses due to the connection of solar PV for both Cases I and II can be calculated based on equation (1). The technical losses for the base network are established based on the equation (2). Then the technical losses of the supply zone can be calculated using equation (3). The technical losses reduction is the difference between the technical losses in the base network and the network with solar PV. The results are as shown in Table 2 and Table 3. The domestic customer dominated supply zone have a technical losses reduction of $1.87 \%$. While the total losses reduction in supply zone with majority commercial customer is $15.15 \%$.

TABLE II

CASE I - REDUCTION IN LVN LOSSES DUE TO SOLAR PV

\begin{tabular}{|c|c|c|c|}
\hline \multirow{2}{*}{ Type } & \multicolumn{2}{|c|}{ Losses(kWh) } & $\begin{array}{c}\text { \% Loss } \\
\text { Reduction }\end{array}$ \\
\cline { 2 - 3 } & Base Case & With Solar PV & $2.48 \%$ \\
\hline LVT-1 & 328.78 & 320.64 & $1.49 \%$ \\
\hline LVT-2 & 692.18 & 681.88 & $1.93 \%$ \\
\hline LVT-3 & 1123.34 & 1101.66 & - \\
\hline LVT-4 & 0 & 0 & - \\
\hline LVT-5 & 0 & 0 & $1.87 \%$ \\
\hline Total & 2144.3 & 2104.18 & \\
\hline
\end{tabular}

TABLE III

CASE II - REDUCTION IN LVN LOSSES DUE TO SOLAR PV

\begin{tabular}{|c|c|c|c|}
\hline \multirow{2}{*}{ Type } & \multicolumn{2}{|c|}{ Losses(kWh) } & $\begin{array}{c}\text { \% Loss } \\
\text { Reduction }\end{array}$ \\
\cline { 2 - 3 } & Base Case & With Solar PV & $1.81 \%$ \\
\hline LVT-1 & 330.54 & 324.56 & $2.73 \%$ \\
\hline LVT-2 & 183.5 & 178.49 & $1.01 \%$ \\
\hline LVT-3 & 237.89 & 235.48 & - \\
\hline LVT-4 & 0 & 0 & $23.13 \%$ \\
\hline LVT-5 & 1259.47 & 968.18 & $15.15 \%$ \\
\hline Total & 2011.4 & 1706.71 & \\
\hline
\end{tabular}

The results clearly indicate that supply zone with predominantly commercial customer loads registers a significantly higher percentage reduction in technical losses due to solar PV. This is due primarily to the load profile of commercial customer loads where its peak demand is during the period which the solar PV generates maximum power resulting in power being fully consumed at the point of generation. The losses reduction is significant because the $\mathrm{PV}$ generation reduces the peak current flow in the network and hence reduce the $\mathrm{I}^{2} \mathrm{R}$ losses.

On the other hand, LVN with domestic customer loads shows an only marginal reduction in technical losses from the connection of solar PV. This is because domestic dominated LVT having peak power at late evening, which is not affected by solar PV generation. Solar PV system installed at domestic dominated LVT will help to reduce the energy flow from upstream network hence reduce the technical losses. Hence, strategically it is more beneficial to connect solar PV to LVT-5 types of LVN compared to LVT3 types of LVN.

Distribution network consists of a large number of LV networks. It is very challenging to simulate each of the networks to access the technical losses level. The proposed approach could be used by utility companies to quantify objectively with acceptable accuracy, the impact of solar PV on technical losses of LVN on a large scale supply zone or at system wide level.

\section{CONCLUSION}

A strategic level approach is presented to study the impact of solar PV on technical losses of LV network using representative networks. The number of representative LVN could be expanded to include more than five types if necessary, depending on the utility practices and guidelines on LVN planning and design. Additionally, more scenarios of solar PV penetration and peak demand could be simulated to improve the accuracy of the assessment results.

With a more objective approach in quantifying the technical losses level of LVN due to solar PV penetration, utility companies would be able to make strategic decisions related to investment strategies for the distribution system, tariff revision exercise, and optimization of distribution network planning/design.

The next part of our research is to develop a methodology to comprehensively assess the impact of solar PV on technical losses of the medium voltage network.

\section{ACKNOWLEDGMENT}

The authors gratefully acknowledge the contributions of Tenaga Nasional Berhad and TNB Research for their financial support in carrying out this research.

\section{REFERENCES}

[1] L. Chin Koon, "Interconnection of embedded generation: the Malaysian experience," in 18th International Conference and Exhibition on Electricity Distribution (CIRED 2005), 2005, no. 4.

[2] M. W. Gustafson, J. S. Baylor, and S. S. Mulnix, "The equivalent hours loss factor revisited," IEEE Trans. Power Syst., vol. 3, no. 4, pp. 1502-1508, 1988.

[3] J. Dickert, M. Hable, and P. Schegner, "Energy loss estimation in distribution networks for planning purposes," in 2009 IEEE Bucharest PowerTech, 2009, pp. 1-6.

[4] M. E. Oliveira, "A Top-Down Approach for Distribution Loss Evaluation," IEEE Trans. Power Deliv., vol. 24, no. 4, pp. 2117-2124, 2009.

[5] L. M. O. Queiroz, M. A. Roselli, C. Cavellucci, and C. Lyra, "Energy Losses Estimation in Power Distribution Systems," IEEE Trans. Power Syst., vol. 27, no. 4, pp. 1879-1887, 2012. 
[6] A. K. Dashtaki, M. R. Haghifam, and S. Member, "A New Loss Estimation Method in Limited Data Electric Distribution Networks," IEEE Trans. Power Deliv., vol. 28, no. 4, pp. 2194-2200, 2013.

[7] J. Goop, M. Odenberger, and F. Johnsson, "Distributed solar and wind power - Impact on distribution losses," Energy, vol. 112, pp. 273-284, 2016.

[8] V. H. Mendez Quezada, J. Rivier Abbad, and T. Gomez San Roman, "Assessment of energy distribution losses for increasing penetration of distributed generation," IEEE Trans. Power Syst., vol. 21, no. 2, pp. 533-540, 2006.

[9] W. A. Omran, M. Kazerani, S. Member, and M. M. A. Salama, "A Clustering-Based Method for Quantifying the Effects of Large OnGrid PV Systems," IEEE Trans. OnPower Deliv., vol. 25, no. 4, pp. 2617-2625, 2010.

[10] A. Soroudi and M. Ehsan, "A possibilistic-probabilistic tool for evaluating the impact of stochastic renewable and controllable power generation on energy losses in distribution networks-A case study," Renew. Sustain. Energy Rev., vol. 15, no. 1, pp. 794-800, 2011.

[11] A. Y. Elrayyah, M. Z. C. Wanik, and A. Bouselham, "Simplified Approach to Analyze Voltage Rise in LV Systems with PV Installations Using Equivalent Power Systems Diagrams," IEEE Trans. Power Deliv., 2016.

[12] D. Z. Fitiwi, L. Olmos, M. Rivier, F. de Cuadra, and I. J. PerezArriaga, "Finding a representative network losses model for largescale transmission expansion planning with renewable energy sources," Energy, vol. 101, pp. 343-358, 2016.
[13] J. Wong, Y. S. Lim, J. H. Tang, and E. Morris, "Grid-connected photovoltaic system in Malaysia: A review on voltage issues," Renew. Sustain. Energy Rev., vol. 29, pp. 535-545, 2014.

[14] A. S. Brouwer, M. Van Den Broek, A. Seebregts, and A. Faaij, "Impacts of large-scale Intermittent Renewable Energy Sources on electricity systems, and how these can be modeled," Renew. Sustain. Energy Rev., vol. 33, pp. 443-466, 2014.

[15] M. Karimi, H. Mokhlis, K. Naidu, S. Uddin, and A. H. A. Bakar, "Photovoltaic penetration issues and impacts in distribution network A review," Renew. Sustain. Energy Rev., vol. 53, pp. 594-605, 2016.

[16] A. Colmenar-Santos, C. Reino-Rio, D. Borge-Diez, and E. ColladoFernández, "Distributed generation: A review of factors that can contribute most to achieve a scenario of DG units embedded in the new distribution networks," Renew. Sustain. Energy Rev., vol. 59, pp. 1130-1148, 2016.

[17] Tony Khristanto Hariadi,P.Jutta Prahara,Surya B. Lesmana and Raouf Saidi,"Energy Efficiency and Policy Analysis for Household in DI Yogyakarta (Yogyakarta special Region) Indonesia," International Journal on Advanced Science, Engineering and Information Technology, vol. 6, no. 3, pp. 329-333, 2016. [Online]. Available: http://dx.doi.org/10.18517/ijaseit.6.3.717.

[18] Nguyen Huy Bich and Bui Tuan Anh,"Developing The Solar Tracking System for Trough Solar Concentrator," International Journal on Advanced Science, Engineering and Information Technology, vol. 6, no. 1, pp. 58-60, 2016. [Online]. Available: http://dx.doi.org/10.18517/ijaseit.6.1.651. 